\title{
The Effect of Community-based Health Intervention Program to Improve Metabolic Disease in Jeju Island
}

\author{
Woo Jin Kim ${ }^{1}$, Sang Hoon Kim², Shin Young Park ${ }^{3}$ \\ ${ }^{1}$ Department of Laboratory Medicine, Cheju Halla General Hospital, Jeju, Korea \\ ${ }^{2}$ Office of External Affairs, Cheju Halla General Hospital, Jeju, Korea \\ ${ }^{3}$ Department of Clinical Laboratory Science, Jeju Halla University, Jeju, Korea
}

\section{제주 지역주민기반 대사성질환 개선 프로그램 중재 효과}

\author{
김우진 ${ }^{1}$, 김상훈 $^{2}$, 박신영 ${ }^{3}$ \\ ${ }^{1}$ 제주한라병원 진단검사의학과, ${ }^{2}$ 제주한라병원 대외협력처, ${ }^{3}$ 제주한라대학교 임상병리과
}

\begin{abstract}
This study investigated the effect of community-based health intervention program to improve metabolic disease in Jeju island. There were 50 obese local residents in the experimental group (body mass index, $\mathrm{BMI} \geq 25 \mathrm{~kg} / \mathrm{m}^{2}$ ). They participated in cooking therapy with nutrition education (4 times), exercise program with proprioceptive neuromuscular facilitation (PNF) and stretching training ( 9 times), and alternative medicine program with healing touch massage ( 3 times) during a 3-week period. To evaluate the effectiveness of the program, body composition, blood lipid profiles, blood glucose, and waist circumference were assessed before and after the intervention program. After the program, the value of total cholesterol (TC), glycosylated hemoglobin (HbA1C), diastolic blood pressure, percent body fat, and waist circumference were decreased, and became the normal value. Especially, $\mathrm{HbA} 1 \mathrm{C}$, percent body fat, and waist circumference were significantly decreased $(P<0.001)$ in the experimental group, while $\mathrm{HbA1C}$, percent body fat, and waist circumference were significantly increased $(P<0.001)$ in the control group $(\mathrm{N}=50)$, who had no intervention. Our results suggest that metabolic syndrome associated markers need intervention program for improving them. In conclusion, although this study did not analyze the effect of the health intervention program and cooking therapy separately, considering the result of this 3-week, short term program, the effect will be more profuse if cooking therapy and exercise program were performed concurrently.
\end{abstract}

Key words: BMI, Community-based, Health program intervention, Metabolic disease, PNF

This is an Open Access article distributed under the terms of the Creative Commons Attribution Non-Commercial License (http://creativecommons.org/licenses/by-nc/4.0) which permits unrestricted non-commercial use, distribution, and reproduction in any medium, provided the original work is properly cited.

Copyright () 2018 The Korean Society for Clinical Laboratory Science. All rights reserved.
Corresponding author: Shin Young Park Department of Clinical Laboratory Science, Jeju Halla University, 38 Halladaehak-ro, Jeju 63092, Korea

Tel: 82-64-741-7403

Fax: 82-64-747-3989

E-mail: shiny@chu.ac.kr

Received: August 7, 2018

Revised $1^{\text {st: }}$ August 20, 2018

Revised $2^{\text {nd }}$ : August 22, 2018

Revised $3^{\text {rd: }}$ : August 22, 2018

Accepted: August 22, 2018
서 론

현대는 기존의 다양한 가치 및 산업 간의 창조적 결합을 통해 새로운 부가가치를 창출하는 '융합’ 의 시대로 사회 전반에서 융 합 트랜드가 가속화 되는 추세이다. 지역농촌의 고령화나 이주 민의 증가 그리고 자발적 경제 활동 도구의 부재와 같은 상황은
새로운 가치창출을 위한 사업 발굴을 필요로 하고 있다. 특히 교 육프로그램이나 생활여건이 도시에 비해 크게 취약한 농촌에서 인구의 고령화는 더 빠르게 진전되고 있어[1], 지역농촌을 위한 다양한 건강프로그램의 적용이 절실함을 보여준다. 지금까지 농촌 지역자원의 힐링 요소를 ‘의학적 중재’를 통해 프로그램화 하여 건강자원화 한 콘텐츠 개발이 부족하므로 농촌지역 주민 
들에게 적용시킬 차별화된 자연치유 - 건강프로그램의 개발 및 확산이 필요하다. 2016년 국민건강보험공단에서 조사하고 2017년 발표한 비만백서에 따르면 제주지역의 남성 비만율이 $48.7 \%$ 로 전국에서 가장 높고, 여성 비만율도 $26.5 \%$ 로 강원 (27.8\%)에 이어 두 번째로 높다고 보고 하였다[2]. 지역별 환경 의 차이로 인하여 섭취하는 식사의 형태와 식품의 구성내용의 차이 뿐 아니라 개인의 습관행태 특히 식생활과 밀접한 관계가 있으므로 육류를 즐기는 제주인의 식습관과 운동 부족이 비만 의 중요한 원인으로 볼 수 있다. 제 6기 국민건강영양조사 자료 를 이용하여 연령별 신체활동과 대사성질환과의 관계를 조사한 결과에서, 연령과 운동 강도가 고밀도지단백콜레스테롤(high density lipoprotein cholesterol, HDL)수치에 미치는 영향을 조사하였다. 정상군의 경우 연령과 운동 강도가 $\mathrm{HDL}$ 수치에 영 향이 없었지만 대사질환군의 경우 연령과 운동 강도가 $\mathrm{HDL}$ 유 지에 중요하므로 특히 고령의 대사질환군의 경우 신체활동이 더 중요함을 알 수 있었다[3]. 걷기 운동은 다양한 종류의 신체활 동 중에서 가장 쉽게 할 수 있고 하루 30 분 정도로도 대사성질환 발생률을 감소시킬 수 있다고 보고되고 있으며[4], 운동과 함께 대사성질환에 가장 도움이 되는 것은 식생활 개선이다. 고위험 군 및 저위험군 대사증후군 직장인 남성을 대상으로 식생활중 재프로그램의 효과를 평가한 보고에서 중재프로그램 실시 전에 비해 실시 후에 고위험군의 BMI, 허리둘레, 혈압, $\mathrm{HDL}$, 당화혈 색소( $\mathrm{HbA1C}$ 가 모두 유의적으로 개선되었으며 여러 중재 요소 중 $1: 1$ 영양 상담이 가장 도움이 된 것으로 보고하였다[5]. 중년 여성 대상 영양교육 및 운동중재 프로그램 및 12 주간 성인 비만 여성을 대상으로 영양교육과 운동 중재를 함께 병행한 비만프 로그램 실시 후에 프로그램 시작 전에 비해 효과가 있음을 보고 하였다 특히 12 주간 성인 비만 여성 대상의 경우 체중감량, $\mathrm{BMI}$, 허리둘레, 체지방율이 모두 유의적으로 감소하였다고 보 고하여 여러 중재 방법들 중 에서도 특히 식사요법과 운동요법 을 병행하는 것이 가장 효과적임을 알 수 있었다[6, 7]. 비만유병 률 증가와 더불어 신체활동 부족은 고혈압, 제 2형 당뇨병, 심혈 관질환 등 대사성질환 발생 위험을 높여 조기 사망으로 이어질 수 있기 때문에 사전 예방과 관리가 절실히 요구된다[8, 9]. 선행 연구들에 의해 진행된 중재연구 결과 성별, 연령층에 관계없이 규칙적인 신체활동 참여와 체력수준 향상은 비만도 감소, 체력 수준 향상 및 건강지표 개선 등에 효과가 있음이 입증되었고 $[10,11]$, 우리나라를 포함하여 전 세계적으로 중재를 위한 다양 한 시도에도 불구하고 비만유병률 및 대사성질환은 계속 증가 되고 있다. 최근에는 보다 효율적인 중재 방법의 시도 중에 가족 기반(family-based) 혹은 시골의 마을 공동체 기반(community- based)을 통해 프로그램에 참여한 가족 혹은 한 마을의 주민 대 부분이 대사성질환 위험요인 중 수축기압, 총콜레스테롤(total cholesterol, TC), 저밀도지단백콜레스테롤 (low density lipoprotein cholesterol, LDL) 및 심폐기능이 유의하게 개선 되어 공동체 기반 프로그램의 유용성을 알 수 있었다 $[12,13]$.

따라서 본 연구에서는 효율적이며 실현 가능한 프로그램 중 재를 위해 마을 기반 프로그램을 활용하여 서로 잘 알고 있는 마 을 주민들을 대상으로 참여도 및 효율성을 높이고자 하였고 대 사질환의 위험요인 중 비만에 해당되는 사람들을 대상으로 프 로그램 중재 후에 변화할 수 있는 유용한 요소들을 평가하고자 하였다. '대사성질환 개선프로그램'에는 식사요법, $1: 1$ 영양상 담, 운동요법 및 근육마사지 등을 포함시켜 3주간의 단 기간의 주요 결과를 분석하여 농촌마을 주민들의 건강증진을 위한 기 초자료 뿐 아니라, 천혜의 자연 환경을 갖춘 제주의 장점을 치유 상품화할수 있는 컨텐츠 개발의 기초자료로 활용하고자 하였다.

\section{대상 및 방법}

\section{1. 연구 대상}

본 연구는 '제주 밭담 자연치유 건강프로그램 개발' 의 기초자 료 제공을 위해 현장 방문 모니터링을 실시하여 제주도내 거주 중인 지역민 100 명을 대상으로 50 명은 실험군, 50 명은 대조군 으로 실험군은 '대사성질환 개선 프로그램'에 자발적으로 참여 한 지역 주민들을 대상으로 진행 되었다.대상자모집은 제주 서 부지역권 거주자 중 BMI 25 이상, 허리둘레 남성 $90 \mathrm{~cm}$, 여성 $85 \mathrm{~cm}$ 이상에 해당되는 사람으로 공고문을 통해 한 달에 걸쳐 지원자를 모집하였다. 연령은 제한되지 않았으나 프로그램의 목적상 성인의 경우 대한비만학회 기준 BMI가 25 이상자를 대 상으로 하였고, 음식알러지가 있거나 근골격계 이상으로 운동 요법이 어려운 사람 그리고 임산부는 대상에서 제외 되었다. 자 발적으로 참가를 원한 실험군은 2017년 11월부터 2017년 12 월까지 3주간 총 9번의 프로그램에 참가하였다. 본 연구는 지역 병원에서 기관생명윤리위원회의 심의를 받아 승인 후수행하였 다(CHH IRB, 2017-L20-01).

\section{2. 연구 내용 및 연구 방법}

\section{1) 사전검사}

검사 당일 연구원들은 직접 해당 지역을 오전에 방문하여 혈 액검사를 위한 공복 혈액샘플 $10 \mathrm{~mL}$ 를 채취 하였다. 최소한 15 분 이상 안정을 취한 다음 안정 시 심박 수와 혈압(FT-200S, 자 원메디칼, Korea), 체중, 신장, 체성분(INBody, Biospace Co., 
Korea) 그리고 허리둘레와 같은 신체특성을 측정하였다. 체성 분으로는 골격근량, 체지방량, 제지방량, 내장지방 그리고 복부 지방률을 측정하였으며 혈액은 혈당(SD Biosensor, BGMS, Korea), HbA1C (SD Biosensor, MultiCare, Korea), TC (SD Biosensor, LipidoCare, Korea) 그리고 HDL (SD Biosensor, LipidoCare, Korea) 분석을 위해 사용되었다.

\section{2) 대사성질환 개선 프로그램}

대사성질환 개선을 위한 자연치유·건강프로그램의 효과성 입증을 위해 실험군의 경우 운동요법 7회, 영양관리 식습관 개 선을 위한 쿠킹테라피프로그램 4회 그리고 대체의학활용 프로 그램인 힐링터치 마사지 프로그램 3회에 참여하도록 유도되었 다. 신체활동을 위한 운동요법은 코어근력 운동 및 밸런스 강화 를 위한 고유수용성신경근촉진(PNF) 트레이닝과 몸을 편안하 게 해주는 스트레칭으로 구성하였다. 전체 9회 프로그램에서 사 전검사, 사후검사를 제외하고 프로그램 운영의 가장 많은 비중 을 부여한 운동프로그램은 유산소운동, 코어근력 운동, 밸런스 강화 운동, 스트레칭으로 구성하여 1회 3시간 주 2회에서 3회 빈도로 3주간 실시하였다. 운동프로그램과 함께 쿠킹테라피 프 로그램을 4회, 힐링터치 마사지 프로그램을 3회 포함시켜 함께 운영하였다. 프로그램 수행 기간 내에 식습관 개선을 위한 개인 별 맞춤형 1:1 상담과 영양관리 교육 그리고 지역식자재를 활용 한 건강한 조리법을 배울수 있는 실습을 통해 음식이 주는 즐거 움으로 체중관리 뿐 아니라 몸과 마음의 건강을 회복시키고자 하였다. 동시에 대사성질환 개선에 좋은 혈 자리 자극으로 아래 쪽으로 몰리는 혈액을 발바닥 자극을 통해 하지에 저류되어 있 는 혈액을 심장으로 보내주고, 발등에 분포되어 있는 반사구를 자극해 혈액순환 촉진 및 노폐물과 독소를 배출시켜 자연치유 력을 높이는 힐링터치 프로그램을 함께 병행함으로써 운동의 효과를 극대화하고자 하였다.

\section{3) 사후검사}

사전검사와 9회의 프로그램참여를 마친 피험자들을 대상으 로 실시하였다. 사전검사와 동일하게 10 시간의 공복 이후 사전 검사 때와 동일한 시간대에 혈액샘플을 채취하였고 사전검사 때와 동일한 내용들을 측정하였다.

\section{3. 자료정리 및 통계분석}

본 연구는 대사성질환개선프로그램에 참가한 실험군 50명 의 사전, 사후 변화와 아무런 중재도 하지 않은 대조군 50명의 사전, 사후 결과를 살펴보기 위해 대상자들의 일반적 특성을 비
교 하였고,각 변인의 평균 및 표준편차를 살펴보았으며 유의수 준은 0.05 를 사용하였다. 3 주 동안 프로그램을 진행 후 대사증 후군의 구성 요소와의 관련성을 분석하였다. 실험군과 대조군 의 개인별 특성인 질병여부, 세끼 식사, 소금섭취, 매운 음식, 편 식 및 운동여부에 대해 설문 조사한 결과와 혈당, $\mathrm{HbA1C}$ 등의 측정 결과들의 분석을 위해 변량분석(ANOVA)을 하였고, 주 효 과 및 상호작용 효과가 관찰되는 경우 효과의 근원을 파악하기 위해 $\mathrm{t}$-분석을 실시하였다(IBM SPSS Statistics 14.0, SPSS Inc., Chicago, IL, USA).

\section{결 과}

\section{1. 대상자의 일반적 특성}

사전, 사후 검사에 참여한 실험군 50 명을 대상으로 개인별 특 성인 질병여부, 세끼 식사, 소금섭취, 매운 음식, 편식 및 운동여 부에 대해 설문 조사한 결과 1 개 이상의 질환을 보유한 피험자 는 모두 28 명이었으며 자신이 인지하는 수준에서 질환을 보유 하지 않은 피험자가 21명이었다. 개인별 특성과 혈당 등 모든 검 사항목에 대해 독립표본 $\mathrm{t}$-검증 및 $\mathrm{ANOVA}$ 분석 결과에서는 검 사 항목과 통계적으로 유의한 차이를 보이는 인자는 없었다. 피 험자의 기본적 특성은 Table 1 과 같다.

\section{2. 신체계측, 혈압측정 및 혈액검사 사전, 사후 결과 변화}

3 주간의 대사성증후군개선프로그램을 통해 나타난 실험군 의 신체적 변화 및 혈액변인의 변화를 Table 2에 프로그램 중재 를 받지 않은 대상군의 변화를 Table 3에 제시하였다.

대사성증후군 실험군의 사전 사후 검사에서 $\mathrm{TC}, \mathrm{HbA1C}$, 이 완기혈압, 체지방 및 허리둘레 수치는 프로그램 실시 후에 유의 한차이를 보여 $(P<0.5,0.01,0.001)$ 대부분 정상범위 내로 감 소하였다. 특히 $\mathrm{HbA} 1 \mathrm{C}$ 의 평균값은 프로그램 실시 전 $6 \%$ 였으 나 프로그램 실시 후 정상범위 내 수치인 $5.8 \%(\triangle=-0.2)$ 로 유 의하게 감소하였다 $(P<0.001)$. 체지방과 허리둘레도 프로그램

Table 1. General characteristics of the subjects (participants, N=50)

\begin{tabular}{lcc}
\hline \multirow{2}{*}{ Variables } & \multicolumn{2}{c}{ Subjects (Mean \pm SD) } \\
\cline { 2 - 3 } & EG & CG \\
\hline Age (years) & $58.3 \pm 10.4$ & $50.5 \pm 11.5$ \\
No. of Males/Females & $23 / 27$ & $34 / 16$ \\
BMI (kg/m $)$ & $25.2 \pm 3.0$ & $25.2 \pm 3.2$ \\
Waist $(\mathrm{cm})$ & $87.1 \pm 8.7$ & $81.1 \pm 8.3$ \\
\hline
\end{tabular}

Abbreviations: EG, Experimental Group; CG, Control Group. 
Table 2. Changes of physical characteristics and blood variables of the subjects during 3 weeks of program participation ( $N=50$ )

\begin{tabular}{|c|c|c|c|c|c|c|}
\hline & Variable & Normal range & Before & After & $\triangle$ & $P$ \\
\hline \multicolumn{2}{|c|}{ Glucose (mg/dL) } & $70 \sim 100$ & $108.5 \pm 26$ & $106.3 \pm 21$ & -2.26 & 0.559 \\
\hline \multicolumn{2}{|c|}{$\mathrm{TC}(\mathrm{mg} / \mathrm{dL})$} & $<200$ & $207.5 \pm 43$ & $198.4 \pm 39$ & -9.08 & $0.028^{\star}$ \\
\hline \multicolumn{2}{|c|}{$\mathrm{HDL}(\mathrm{mg} / \mathrm{dL})$} & $<40$ & $52.6 \pm 14$ & $50.8 \pm 12$ & -1.73 & 0.352 \\
\hline \multicolumn{2}{|c|}{$\operatorname{HbA} 1 \mathrm{c}(\%)$} & $4 \sim 6 \%$ & $6.0 \pm 0.8$ & $5.8 \pm 0.8$ & -0.20 & $0.010^{\star *}$ \\
\hline \multicolumn{2}{|c|}{ Systolic blood pressure (mmHg) } & $<130$ & $132.6 \pm 14.7$ & $129.1 \pm 18.7$ & -3.47 & 0.163 \\
\hline \multicolumn{2}{|c|}{ Diastolic blood pressure (mmHg) } & $<85$ & $85.1 \pm 7.2$ & $82.3 \pm 9.4$ & -2.73 & $0.022^{*}$ \\
\hline \multirow[t]{5}{*}{ In Body } & Skeletal muscle (\%) & $24 \sim 39$ & $25.9 \pm 5.4$ & $26.1 \pm 5.4$ & +0.07 & 0.644 \\
\hline & Body fat (\%) & - & $28.3 \pm 6.69$ & $19.8 \pm 7.02$ & -8.49 & $0.000^{\star \star \star}$ \\
\hline & Fat free mass (\%) & - & $47.1 \pm 8.9$ & $47.2 \pm 8.9$ & +0.17 & 0.180 \\
\hline & Visceral fat $(\%)$ & - & $7.88 \pm 2.87$ & $7.69 \pm 2.85$ & -0.19 & 0.067 \\
\hline & Abdominal fat (\%) & - & $0.870 \pm 0.048$ & $0.870 \pm 0.044$ & 0.00 & 1.000 \\
\hline \multicolumn{2}{|c|}{$\mathrm{BMI}\left(\mathrm{kg} / \mathrm{m}^{2}\right)$} & $<25$ & $25.26 \pm 2.95$ & $25.21 \pm 2.94$ & -0.05 & 1.000 \\
\hline \multicolumn{2}{|c|}{ Waist circumference $(\mathrm{cm})$} & $<90$ & $87.1 \pm 8.7$ & $85.2 \pm 9.0$ & -1.83 & $0.000^{\star \star *}$ \\
\hline
\end{tabular}

The values are Mean $\pm S D(N=50)$.

${ }^{*} P<0.05,{ }^{*} P<0.01,{ }^{*} * * P<0.001$.

Table 3. Changes of physical characteristics and blood variables of the control subjects with no intervention participation ( $N=50)$

\begin{tabular}{lccccc}
\hline \multicolumn{1}{c}{ Variable } & Normal range & Before & After & $\triangle$ & $P$ \\
\hline Glucose $(\mathrm{mg} / \mathrm{dL})$ & $70 \sim 100$ & $98.6 \pm 12$ & $106.9 \pm 28$ & 8.16 & $0.031^{*}$ \\
TC (mg/dL) & $<200$ & $199.3 \pm 37.5$ & $226.7 \pm 43.4$ & 27.4 & $0.000^{\star \star *}$ \\
HDL (mg/dL) & $<40$ & $51.7 \pm 12.1$ & $52.4 \pm 12.8$ & 0.68 & 0.550 \\
HbA1C (\%) & $4 \sim 6 \%$ & $5.5 \pm 0.6$ & $5.6 \pm 0.8$ & 0.08 & 0.347 \\
Systolic blood pressure (mmHg) & $<130$ & $120.7 \pm 13.4$ & $116.8 \pm 16.6$ & -3.92 & 0.160 \\
Diastolic blood pressure (mmHg) & $<85$ & $78.1 \pm 14.8$ & $78.7 \pm 11.0$ & 0.60 & 0.770 \\
In Body Skeletal muscle (\%) & $24 \sim 39$ & $27.5 \pm 6.2$ & $32.1 \pm 29.4$ & 4.61 & 0.283 \\
$\quad$ Body fat (\%) & - & $27.2 \pm 5.9$ & $27.6 \pm 6.9$ & 0.44 & 0.067 \\
$\quad$ Fat free mass (\%) & - & $47.1 \pm 8.9$ & $47.2 \pm 8.9$ & +0.17 & 0.180 \\
$\quad$ Visceral fat (\%) & - & $7.88 \pm 2.87$ & $7.69 \pm 2.85$ & -0.19 & 0.067 \\
Abdominal fat (\%) & - & $0.920 \pm 0.041$ & $0.920 \pm 0.040$ & 0.005 & $0.016^{*}$ \\
BMI (kg/m ${ }^{2}$ ) & $<25$ & $25.17 \pm 3.2$ & $25.32 \pm 3.24$ & +0.156 & 0.150 \\
Waist circumference (cm) & $<90$ & $81.1 \pm 8.3$ & $83.8 \pm 10.0$ & 1.66 & $0.014^{*}$ \\
\hline
\end{tabular}

The values are Mean $\pm \mathrm{SD}(\mathrm{N}=50)$.

${ }^{\star} P<0.05,{ }^{\star \star} P<0.01,{ }^{\star \star \star} P<0.001$.

실시 전에 비해 유의하게 감소하였다 $(P<0.001)$. 프로그램 실 시 후에 $\mathrm{HbA1C}$, 체지방, 허리둘레는 각각 $30 \%, 33 \%, 33 \%$ 의 감 소율을 보였다. 운동과 음식의 중재를 받지 않은 대조군에서 실 험군의 결과와 가장 큰차이를 보인 것은 TC와 허리둘레 수치였 다. 대조군의 사후검사에서는 실험군에서 유의하게 감소된 것 과 반대로 199.3 이었던 TC 수치가 3 주 후에 226.7로 27.4가 증 가 되었으며 $(\triangle=+27.4$ ) 허리둘레 또한 81.1에서 83.8로 3주 후 에 오히려 증가 $\triangle=+0.2)$ 되었다. 실험군에서 중재 후에 TC 수 치가 유의하게 감소되어 모두 정상범위 내에 있는 것과 달리 대 조군은 $14 \%$ 의 증가율을 보이며 평균값이 정상치의 범위를 벗 어나는 네가티브 유의성을 보였다 $(P<0.001)$. 또한 혈당과 복 부지방도 아무런 중재를 하지 않은 대조군의 경우 3 주 후에 각 각 8.16( $\triangle), 0.005(\triangle)$ 증가되어 네가티브 유의성을 보였다 $(P<$ 0.05). $\mathrm{HbA1C}$ 도 대조군의 경우 사후검사에서 실험군과 달리
증가하는 소견을 보였으나 유의성은 없었다. 그러나 골격근량 의 경우 실험군에서는 변화가 없었는데 대조군에서는 약간의 증가 $\triangle=+4.61)$ 를 보였으나 유의성은 없었다.

\section{고 찰}

일반적 관점에서 생각하면 농촌지역 주민들이 도시 거주 주 민 보다좀 더 건강할 것이고 대사성관련 질환도 적을 것으로 생 각되나 최근의 도시와 농촌의 대사증후군 유병률의 보고에 따 르면 도시지역 대사증후군 유병률은 23.4\%, 농촌지역은 29.0\% 로 농촌지역이 유의하게 높은 유병률을 보였다고 한다[14]. 외 국의 경우 도시 지역 유병률이 높다는 연구결과가 더 많은데 $[15,16]$ 비해 우리나라는 농촌지역 유병률이 더 높은 원인이 인 구구성차이로 도시에 비해 농촌이 노인 연령층의 인구비율이 
높았기 때문이라고 보았다. '대사성질환 개선프로그램'을 이용 하여 제주밭담 농촌체험 건강프로그램의 개발을 위해 시행된 운동과 쿠킹테라피를 결합한 건강프로그램이 비교적 짧은 기간 인 3 주 동안 총 9회에 걸쳐 진행되었다. 실험군에서의 대사성질 환 관련 수치의 전후 변화를 볼 때 통계적으로 유의한 개선이 있 었던 항목은 $\mathrm{TC}, \mathrm{HbA1C}$, 이완기혈압, 체지방, 허리둘레였다. 심박 수와 혈압반응을 보이는 대사증후군에서는 운동에 의해 높은 심근부담률을 보일 수 있기 때문에 심혈관 위험이 내재되 어 있는 대사증후군 질환자에게 운동부하 검사를 통한 심근부 담률의 평가는 중요한 의미가 있어[17] 운동부하 검사 시 심근 부담률의 적정 임계점을 제시하여 목표치를 제시하여 보고된 연구도 있는데[18] 본 프로그램 적용자의 이완기 혈압이 유의하 게 감소된 것은 의미가 있을 것으로 생각된다 $(P<0.05)$. 그 외에 도 비록 통계적 유의성은 없었으나 프로그램 전에 비해 개선효 과가 있었던 항목으로는 혈당, 수축기 혈압, 골격근, 제지방, 내 장지방이었다. 결과적으로 대사성질환 관련 총 12 개 지표 중 유 의한 변화가 없었던 $\mathrm{HDL}$ 과 복부지방을 제외한 전 항목에서 개 선이 있었는데 총 9회라는 적은 횟수의 시행을 고려하면 상당히 의미 있는 변화였다. 대조군과의 비교를 해보면 그 변화의 의미 는 더욱 커진다. 대조군의 경우 통계적으로 유의한 악화가 있었 던 항목은 혈당, 총콜레스테롤, 복부지방, 허리둘레였고 통계적 유의성은 없었으나 악화가 있었던 항목으로는 당화혈색소, 이 완기혈압, 체지방, 내장지방으로 측정지표 12 개중 8항목에서 악화가 있었다. 이런 결과를 놓고 볼 때 대사성질환 관련 지표는 아무 개입이 없으면 악화되는 경향이 있고, 식이나 운동을 실시 하면 의미 있게 개선되는 경향이 있음을 알 수 있다. 그러나 운동 중재에도 불구하고 실험군의 경우 골격근량이 변화가 거의 없 었던 것은 체중감량과 단기간의 중재가 원인일 것으로 생각된 다. 이는 프로그램 중재 후에 유의한 변화는 아니었지만 BMI가 감소 $(\triangle=-0.05)$ 되었고 대조군에서 골격근량이 증가된 것은 체중의 증가로 BMI가 증가 $\triangle=+0.156)$ 되었기 때문이다. 추가 적으로 실험군에서 생활습관별로 세부 분석해 본 결과를 보면 대사성질환 관리에 보건교육의 중요성을 알 수 있다. 비록 설문 지법이고 관찰기간이 짧아 통계적 유의성이 있을 만큼의 차이 는 없었지만 참고할 만한 경향은 발견할 수 있었다. 대표적인 예 로 대사증후군의 중요한 지표인 혈당이나 $\mathrm{HbA1C}$, 수축기 혈압 의 경우 질병이 있을 때, 세끼 식사, 짠 음식, 운동을 안 할 때 높 은 경향이 있었다. 하지만 기타 항목의 경우 좋은 습관과도 연관 되는 경향이 있어 설문지를 보다 객관성 있고 세부적으로 개량 하고 관찰기간을 늘려 실시하게 되면 보다 정확한 결론을 도출 할 수 있을 것으로 예상된다. 최근에 대사성질환자들의 심혈관
합병증 발생률을 경감시킬 수 있는 가장 중요하면서도 가장 비 용 효과적인 방법으로 치료적 생활습관개선(therapeutic lifestyle modification, TLM)이 강력히 권고되면서 이들을 위 한 TLM의 개발을 위해 우선적으로 근거자료의 확보가 필요함 을 강조하였다[19]. 본 연구에서는 점차 증가하고 있는 대사성 질환의 유병률, 농촌지역 인구의 감소 상황 등을 고려해 건강한 농촌, 활력이 넘치는 농촌을 위한 쿠킹테라피와 운동 요법을 단 기간 실시하였는데 대조군에 비해 대사증후군 관련 지표 대부 분이 개선되는 효과를 발견할 수 있었고 추가적으로 보건교육 의 중요성도 일부 확인할 수 있었다. 동시에 생활적습관의 변화 로 대사증후군관련지표들이 유의하게 개선되고 악화를 예방하 는 경향을 보여 TLM 개발을 위한 근거자료의 토대를 마련하고 향후 휴양을 결합한 자연치유 건강산업의 시너지 효과를 극대 화 하면서 천혜의 자연 환경을 갖춘 제주의 장점을 치유상품화 할 경우, 유효한 농촌 체험 건강프로그램이 될 가능성을 보여 주 었다고 판단된다.

그러나 본 연구에서는 한 마을 기반 프로그램으로 지역의 한 개의 마을만을 대상으로 제한된 범위의 피험자에서 이상지혈증 으로 약을 복용하고 있는 사람들까지 제외해야 하므로 대사증후 군의 주요 인자인 중성지방의 측정을 할 수 없어 대사증후군에 대 한 관련성을 검증할 수 없었다. 동시에 이미 많은 보고에서 비만 과 관련된 당뇨병, 심혈관질환과같은 대사질환의 발병에 중요한 역할을 한다고 밝혀진[20, 21] 혈중 아디포넥틴(adiponectin) 농도를 측정하지 않았다는 점을 연구의 제한점으로 들 수 있다. 보고에 따르면 식사조절과 운동을 병행하였을 때 체중 및 체질량 지수를 감소와함께 혈중 아디포넥틴의 농도 역시 유의적으로 증 가되어 체질량지수, 중성지방농도, 당뇨병이나 심혈관질환의 유 무가 혈장 아디포넥틴의 농도와 유의한 상관관계가 있음을 밝혔 다[22, 23]. 이상의 제한점에도 불구하고 본 연구 결과로 부터 3 주간의 짧은 중재기간임에도 불구하고 실험군의 경우 사전, 사후 비교에서 중재를 통한 효과가 있음을 알 수 있었다. 향후 보다 많 은 대상군을 확보하여 제한점 보완 후 연구가 진행되어야할 것이 다.

\section{요 약}

본 연구는 대사성질환 관련 위험 인자를 가지고 있는 제주 지 역주민을 대상으로 마을 기반 건강프로그램의 효과성을 입증하 기 위해 수행되었다. 50 명의 실험군은 BMI가 25 이상인 지역주 민으로 3주 동안 고유수용성신경근촉진(PNF) 트레이닝과 스트 레칭을 포함한 운동요법 7회, 영양관리 식습관 개선을 위한 쿠 
킹테라피 프로그램 4회 그리고 대체의학활용 프로그램인 힐링 터치 마사지 프로그램 3회의 건강중재프로그램에 참여하였다. 건강프로그램 중재의 효과성 평가를 위해 프로그램 중재 전과 후에 체 성분, 혈액의 지질 프로파일, 혈당 및 허리둘레를 측정 하여 비교하였다. 건강프로그램 중재 후에는 중재 전에 비해 $\mathrm{TC}, \mathrm{HbA1C}$, 이완기혈압, 체지방 그리고 허리둘레가 크게 감소 하여 거의 정상수치가 되었고 특히 $\mathrm{HbA1C}$, 체지방 그리고 허리 둘레는 유의한 수준으로 감소 $(P<0.001)$ 되었다. 그러나 반대 로 건강프로그램 중재를 받지 않은 대상군의 경우 $\mathrm{HbA1C}$, 체지 방 및 허리둘레가 유의한 수준으로 증가 $(P<0.001)$ 하는 부정 적 결과를 보였다. 이상의 결과로부터 대사성질환 관련 인자들 은 건강프로그램의 중재로 개선되어 호전될 수 있음을 알 수 있 었다. 본 연구에서는 건강중재프로그램인 운동과 쿠킹테라피 효과를 구분하여 조사하지는 않았지만 3주간의 단기간에 보여 진 효과가 두 가지를 병행해서 수행함으로써 나타난 결과임을 암시하며 식사조절과 운동을 병행하는 것이 대사성질환 개선에 보다 효과적임을 제시하고자 한다.

Acknowledgements: This work was supported by the Jeju City Regional Development Committee Program (Leading Local Project for Happy Living Zone). And we also thank Hyun-Ji Kim for her research assistance.

Conflict of interest: None

\section{REFERENCES}

1. Kim SE. Impacts of ageing society on local administration and its preparation for the future. Local administration study. 2017;31:3-034.

2. National Health Insurance Service. Obesity white paper. 2017. p41-127.

3. Lim HK, Sull JW, Park JY, Hong MH, Lee YR, et al. Relationship of metabolic diseases with physical activity depending on age. Korean J Clin Lab Sci. 2018;50:144-154. https://doi.org/10.15324/ kjcls.2018.50.2.144.

4. Oja P, Vuori I, Paronen O. Daily walking and cycling to work: their utility as health-enhancing physical activity. Patient Educ Couns. 1998;33(Suppl 1):87-94.

5. Kim HJ, Choi IJ, Kim WG, Asano K, Hong JM, Cho YM, et al. Effect of a worksite-based dietary intervention program for the management of metabolic syndrome. KJCN. 2016;21:237-246. https://doi.org/10.5720/kjcn.2016.21.3.237.

6. Choi MS. Effects of nutrition education and exercise intervention on health and diet quality of middle-aged women. Korean J Nutr. 2009;42:48-58. https://doi.org/10.1186/14712458-9-45.

7. Lee HS, Lee JW, Chang NS, Kim JM. The effect of nutrition edu- cation and exercise program on body composition and dietary intakes, blood lipid obese women. Korean J Nutr. 2009;42: 759-769. https://doi.org/10.5720/kjn.2009.42.8.759.

8. Mottillo S, Filion KB, Genest J, Joseph L, Pilote L, Poirier P, et al. The metabolic syndrome and cardivascular risk a systematic review and mata-analysis. J Am Coll Cardiol. 2010;56:11131132. https://doi.org/10.1016/j.jacc.2010.05.034.

9. Jekal Y, Yun JE, Park SW, Jee SH. Jeon JY. The relationship between the level of fatness and fitness during adolescence and the risk factors of metabolic disorders in adulthood. Korean diabetes J. 2010;34:126-134. https://doi.org/10.4093/kdj.2010. 34.2.126.

10. Ko SH, Park CH, Jekal US. Effects of exercise intervention program on the level of obesity, physical fitness level and metabolic related risk factors among hypertensive and diabetic patients. Korea Society for Wellness. 2017;12:645-655. https://doi.org/ 10.21097/ksw.2017.02.12.1.645.

11. Williams PT. Physical fitness and activity as separate heart disease risk factors: a meta-analysis. Med Sci Sports Exerc. 2001;33:754-761.

12. Park $\mathrm{CH}$, Jekal Y. The effect of family-based health promotion programm on the level of obesity, physical fitness and metabolic related risk factors among children and adolescents. Korea Society for Wellness. 2017;12:565-578. https://doi.org/ 10.21097/ ksw.2017.08.12.3.565.

13. Wang Y, Xie B, Tao Y, Ma Y, Zang K. Impact of community-based integrated traditional chinese and Western medicine metabolic symdrome intervention technology in rural residents in Southern Jiangsu, China. Clini Res. 2015;2163-2169. https:// doi.org/10.12659/MSM.893972.

14. Kim MJ, Park EO. The prevalence and the related factors of metabolic syndrome in urban and rural community. Korean J of Adult Nurs. 2014;26:67-77.

15. Weng X, Liu Y, Ma J, Wang W, Yang G, Caballero B. An urban-rural comparison of the prevalence of the metabolic syndrome in Eastern China. Public Health Nutrition. 2007;10:131136. https://doi.org/10.1017/S1368980007226023.

16. Zyl S, Merwe LJ, Walsh CM, Groenewald AJ, Rooyen FC. Risk-factor profiles for chronic diseases of lifestyle and metabolic syndrome in an urban and rural setting in South Africa. Afr J Prm Health Care Fam Med. 2012;4:1-10. https://doi.org/ 10.4102/phcfm.v4i1.346.

17. Rossi AM, Davies E, Lavoie KL, Arsenault A, Gordon JL, Meloche $\mathrm{B}$, et al. The impact of metabolic syndrome and endothelial dysfunction on exercise-induced cardiovascular changes. Obesity. 2013;21:143-148. https://doi.org/10.1002/oby.20258.

18. Shin KA. Optimal cutoff points of rate pressure product in each stage of treadmmill exercise test according to the degree of metabolic syndrome in Korean adults. Korean J Clin Lab Sci. 2018;50:136-143. https://doi.org/10.15324/kjcls.2018.50.2.136.

19. Grundy SM, Cleeman JI, Merz CN, Brewer HB, Clark LT, Hunninghake DB, et al. Implication of recent clinical trials for the national cholesterol education program adult treatment panel III guideline. Circulation. 2004;110:227-239. https://doi.org/ 10.1161/01.ATV.0000133317.49796.0E.

20. Rabe K, Lerke M, Parhofer KG, Bredl UC. Adipokines and insulin resistance. Mol Med. 2008;14:741-751. https://doi.org/10.2119/ 
2008-00058.Rabe.

21. Lindsay RS, Funahashi T, Hanson RI, MatsuzawaY, Tanaka S, Tataranni PA, et al. Adiponectin and development of type 2 diabetes in the Pima Indian population. Lancet. 2002;360:57-58. https://doi.org/10.1016/S0140-6736.

22. Wijesekara N, krishnamurthy M, Bhattacharjee A, Suhail A, Sweeney G, Wheeler MB. Adiponectin-induced ERK and Akt phosphorylation protects against pancreatic beta cell apoptosis and increases insulin gene expression secretion. J Biol Chem 2010;285:33623-33631. https://doi.org/10.1074/jbc.M109.085084.

23. Hans JS, Zhoh CK, Lee EJ. The effect of obesity management program on blood lipid profile and adiponectin in obese women. Korean J Obes. 2013;22:231-236. http://dx.doi.org/ 10.7570/kjo.2013.22.4.2311. 